\title{
The effect of He-Ne Laser and UVC irradiation on sperm head morphology and DNA of testis for albino mice(Mus musculus)
}

\author{
Shayma`a Jamal Ahmed(Ph.D) ${ }^{1}$, Al-Siaidy W. F (Ph.D $)^{2}$, \\ Rawah. A. Faraj (M. Sc.) ${ }^{3}$ \\ 1 Anatomy Depart. College of Medicine. Baghdad University. Iraq. \\ 2 Physics Depart. College of Medicine. Baghdad University. \\ 3 Community Health ,Institute of Technical Medicine Foundation Of Technical Education
}

\begin{abstract}
In vitro, He-Ne laser show a modifying response of cells to ionizing radiations. So there is a need to investigate this property in vivo.To investigate the effect of He-Ne laser $(632.8 \mathrm{~nm})$ pre and post irradiation against the UVC (253.7nm) irradiation in vivo on the sperm morphology, and DNA of testis in Mouse.

In this study Twenty adult albino male mice were divided into four groups, the first group was He-Ne laser irradiated, and the second group was UVC irradiated. The third group was pre-irradiated by He-Ne laser followed by UVC irradiation, with one hour time interval between the two irradiations. The fourth group was pre-irradiated by UVC then by He-Ne laser, with one hour separating the two irradiations.

The He-Ne laser per-irradiation show a protection properties, which appeared on both sperm head abnormality and DNA damage against UVC light irradiation.

Four sperm head abnormality features were found after each type of irradiation. But the He-Ne laser preirradiation against UVC irradiation lower the frequencies of sperm head abnormality, farther more reduce the DNA testis damaging.

Both UVC and He-Ne laser irradiations revealed a toxic effect on sperm head morphology, but the He$\mathrm{Ne}$ laser was found less effective. The He-Ne laser protective properties was observed only when He-Ne laser irradiation was applied before the UVC irradiation.

Key words: He-Ne Laser, UVC irradiation, sperm head morphology, DNA.
\end{abstract}

\section{Introduction:}

Various Laser wavelengths with different powers, and exposure times have been used in medicine. But the low level (power) Laser of wavelengths ranging from red to infra-red light have been used in therapy, as a non-destractive fashion. Since light of these wavelengths have less photon energy to provide biomolecular ionization or damaging. So the low level laser observed healing process in tissue repair as a results of biostmulation $(1,2)$.

The most commonly used laser is the Helium- Neon (He-Ne) laser of wavelength $632.8 \mathrm{~nm}$. In vitro, this laser showed a modifying response of cells to ionizing radiation such as $\mathrm{\gamma}$-ray(3),X-ray(4) and ultraviolet (UV) light(5). But a protective properties was found to be more significant when laser radiation was performed prior exposure to ionizing radiation $(6,7,8)$.

Since UV spectrum is divided into three general categories bases on the UV wavelength: UVA $>320 \mathrm{~nm}$, $\mathrm{UVB}(280-320 \mathrm{~nm})$ and UVC $<280 \mathrm{~nm}(9)$. But the UV radiation using any one of these categories, can trigger a variety of effects either through:

A direct DNA damage (10), or via the generation of the free radicals and reactive Oxygen species in nucleus, plasma membrane, cytoplasm and mitochondria(11) , and or through the activation of the genetics agents (P53-gen) in cells (12).

The formation of pyrimidin dimmers on DNA that provokes changes in the conformation of DNA, this may impairing its genomic contribution in the egg during fertilization (13). UVC radiation continually being used for irradiation eggs, to establish the appropriate dose to be used for complete sperm DNA inactivation (14).

In vitro, the He-Ne laser protective properties against UV light on different cells develop a potential to study this effect on sperms, and DNA. So the aim of this work is to investigate the effect of He-Ne laser pre and post irradiation against the UVC irradiation in vivo on the sperm morphology, and DNA of testis in Mouse.

\section{Research Methods:}

Since cells protection or modification depend on He-Ne laser, and UVC irradiation doses (exposure times) pluse the period separating the two irradiation (15). Where no protection was observed when no interval 
time was given between the two irradiation, but a significant one was noticed when the time was greater than 30 mints (3).

In the current study, the He-Ne laser, UVC doses, and the separation time between the two irradiation are kept fixed. The UVC lamp from Philps of $253.7 \mathrm{~nm}$ wavelength, and a power of $20 \mathrm{Watt}(\mathrm{W})$ was used. The He-Ne laser of wavelength $632.8 \mathrm{~nm}$ with a maximum output power of $0.5 \mathrm{~mW}$ ( Industrial Fiber Optics IFHIV) was employed.

\section{2-1 Animals experiments :}

In order to assess the influence of He-Ne laser plus the UVC irradiation on testis of Mouse the following experiments were performed.

Twenty adult of albino male mice, weight (25-35 gm), were used in this study. These mice were isolated in a relatively controlled environment at temperature of about $25^{\circ} \mathrm{C}$ at the "Animal breeding centercollege of Medicine-Baghdad University". They were given food and free access to water. The mice were divided into four groups, each group consist of 5 mice.

1- First group: was employed to study the influence of He-Ne laser irradiation. A continuous He-Ne laser of wavelength $632.8 \mathrm{~nm}$ with a maximum output power of $0.5 \mathrm{~mW}$, and a beam spot area of $1 \mathrm{~mm}^{2}$, was employed. The laser beam was directed on testis for a period of 10 seconds, which equal to energy dose of( $5 \times 10^{-2} \mathrm{~J} / \mathrm{cm}^{2}$ or $5 \times 10^{2} \mathrm{~J} / \mathrm{m}^{2}$ ).

2- Second group: was used to characterize the degree of UVC irradiation on mice testis. The UVC source placed $30 \mathrm{~cm}$ above the mouse cage, where the final UVC power at the mouse skin surface was $1.2 \mathrm{~mW}$, for $5 \mathrm{~min}$.

The combined action of He-Ne laser, and UVC irradiation were done according to the following steps on mice.

3- Third group: was pre-irradiated by He-Ne laser $\left(5 \times 10^{2} \mathrm{~J} / \mathrm{m}^{2}\right)$ followed by UVC irradiation (5 min) with one hour time interval between the two irradiations.

4- Fourth group: was pre-irradiated by UVC light for $5 \mathrm{~min}$. After one hour, this group was irradiated by $\mathrm{He}-\mathrm{Ne}$ laser of $5 \times 10^{2} \mathrm{~J} / \mathrm{m}^{2}$.

\section{2-2 Sperm head abnormalities:}

Animals were sacrificed, after $15 \mathrm{~min}$ of the final irradiation, according to Banerjee method through cervical disocation(16). Testes and epididymis were removed and cleaned of accessory tissues, and weighed. Then minced with a scissor, and suspended in $0.8 \mathrm{ml}$ of $(0.87 \%)$ normal saline kept at $37^{\circ} \mathrm{C}$. Several drops of suspension were smeared on clean glass slides. After air drying, the smears were stained in (1\%) eosin stain. Then the number of abnormal sperm head was examined, and counted.

\section{2-3 DNA extraction:}

DNA was extracted from testis for mice using Bioneer-Korea Kit. The DNA concentration was measured by using Ultra violated spectrophotometer (CECIL, CE 7200). Finally the DNA was electrophoresed using $1 \%$ agrose gel electrophoresis, at $3 \mathrm{~V} / \mathrm{cm}$, for $90 \mathrm{~min}$.

\section{Results:}

The percentage of sperm head abnormalities are summarized in the table 1. The abnormal sperm head features found in this study are illustrated in Fig.1. The DNA electrophoresis results are demonstrated in Fig. 2.

Table1

The percentage of sperm head abnormality after irradiation

\begin{tabular}{|l|l|l|l|l|l|}
\hline Type of radiation & $\begin{array}{l}\text { Normal } \\
\text { Sperm } \\
(\%)\end{array}$ & $\begin{array}{l}\text { No head } \\
(\%)\end{array}$ & $\begin{array}{l}\text { Thread head } \\
(\%)\end{array}$ & $\begin{array}{l}\text { Balloon head } \\
(\%)\end{array}$ & $\begin{array}{l}\text { Curved head } \\
\text { \& no hook } \\
(\%)\end{array}$ \\
\hline Laser & 24.8 & 11.3 & 22.2 & 28.2 & 13.5 \\
\hline UVC & 18.3 & 20.1 & 24.5 & 15 & 22.1 \\
\hline Laser+ UVC & 22.4 & 8 & 17.1 & 31.2 & 19.3 \\
\hline UVC+ Laser & 15.1 & 17.5 & 21.1 & 23.2 & 24.1 \\
\hline
\end{tabular}




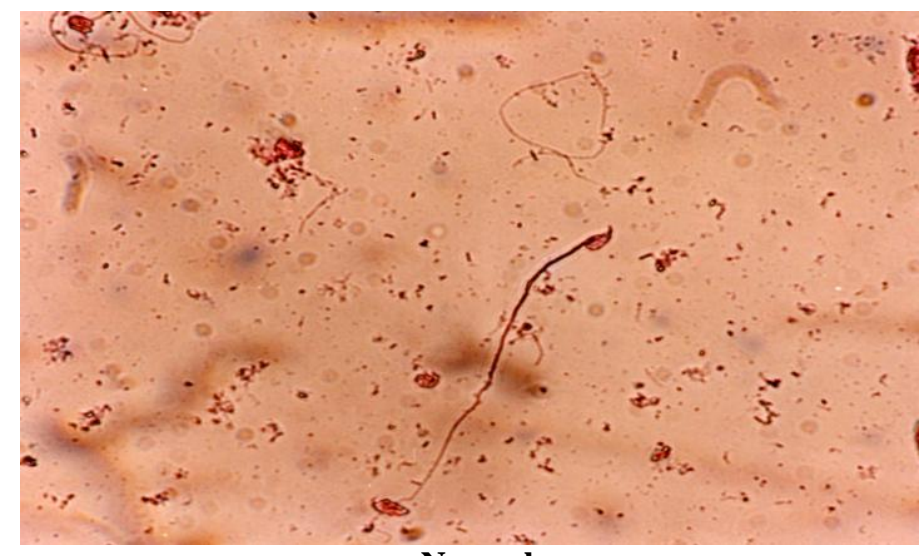

a- Normal sperm
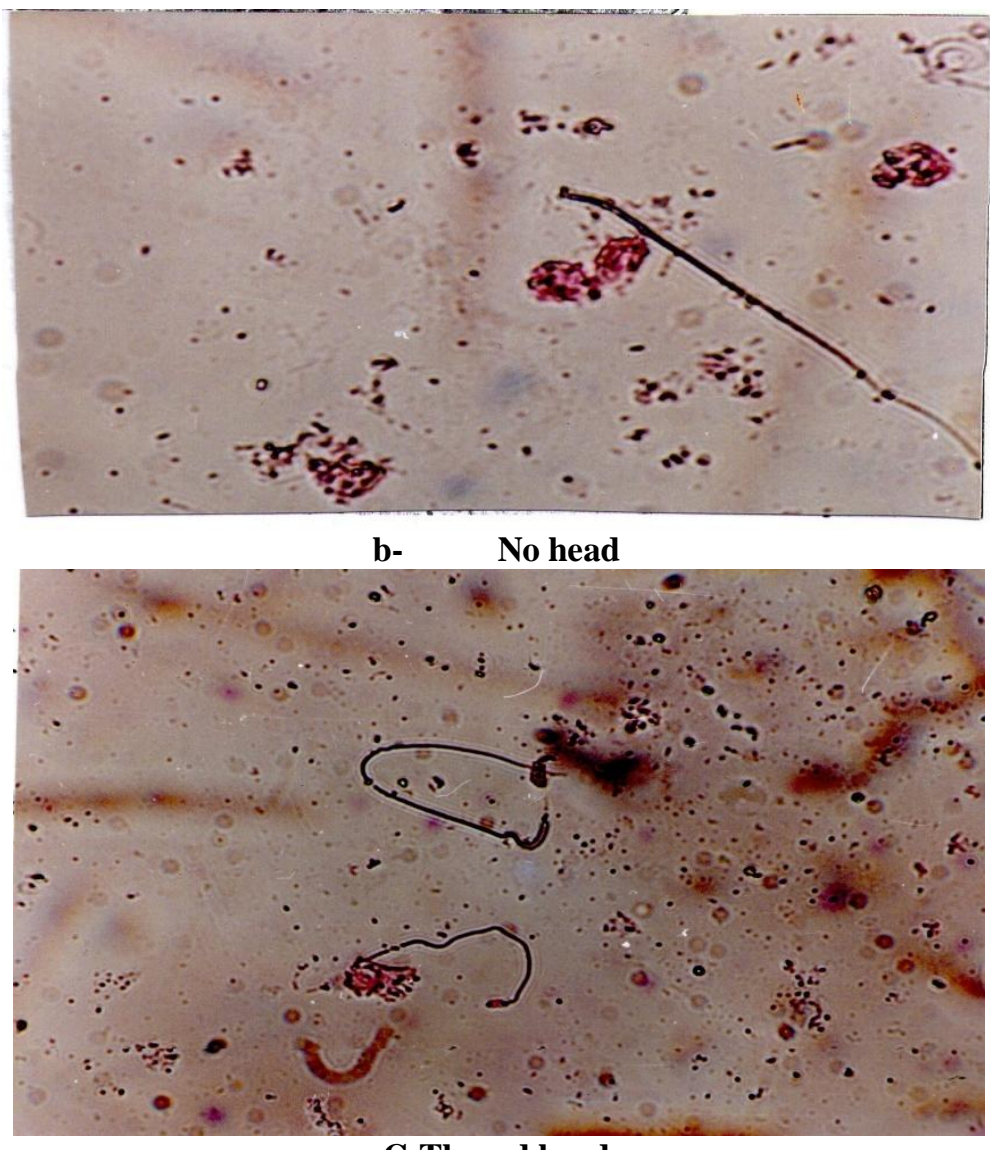

\section{C-Thread head}

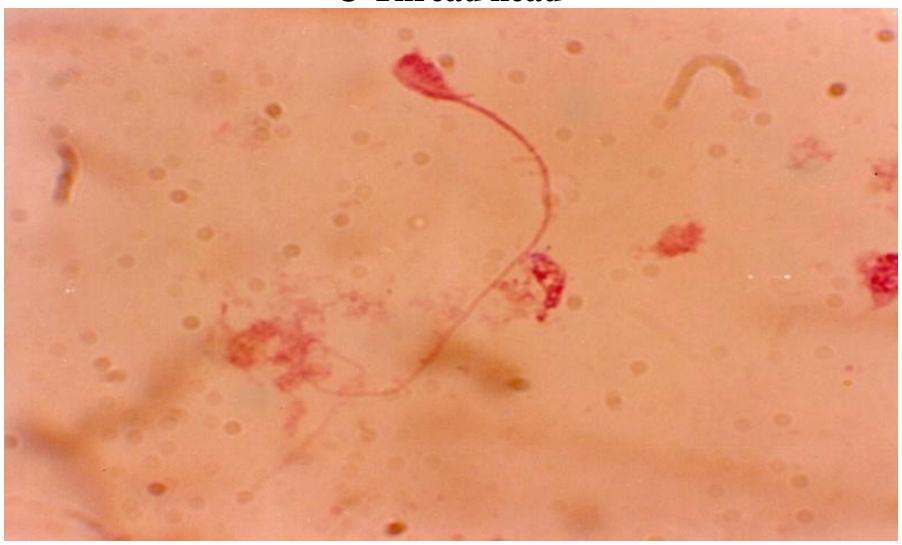

D- Balloon head 


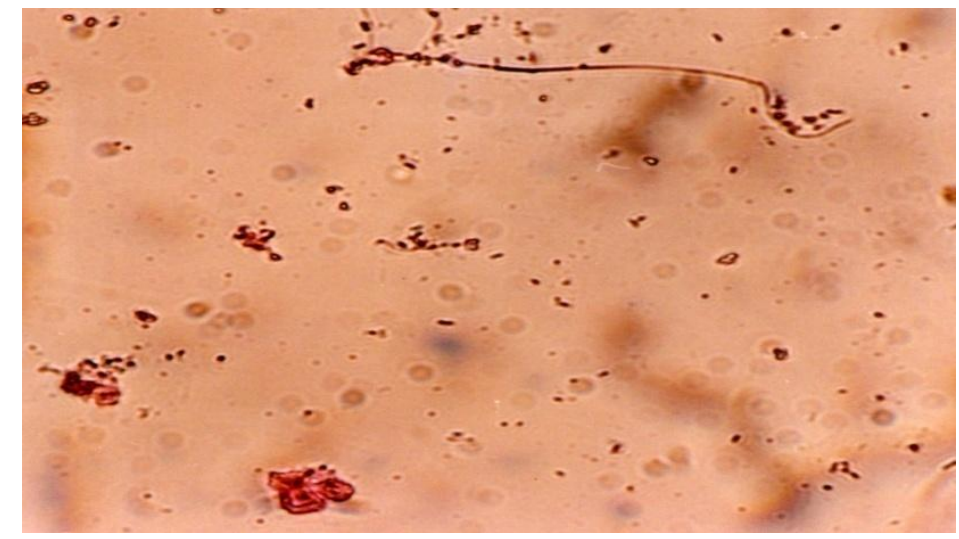

E- Curved head \& no hook

Fig.1. The sperm head abnormality

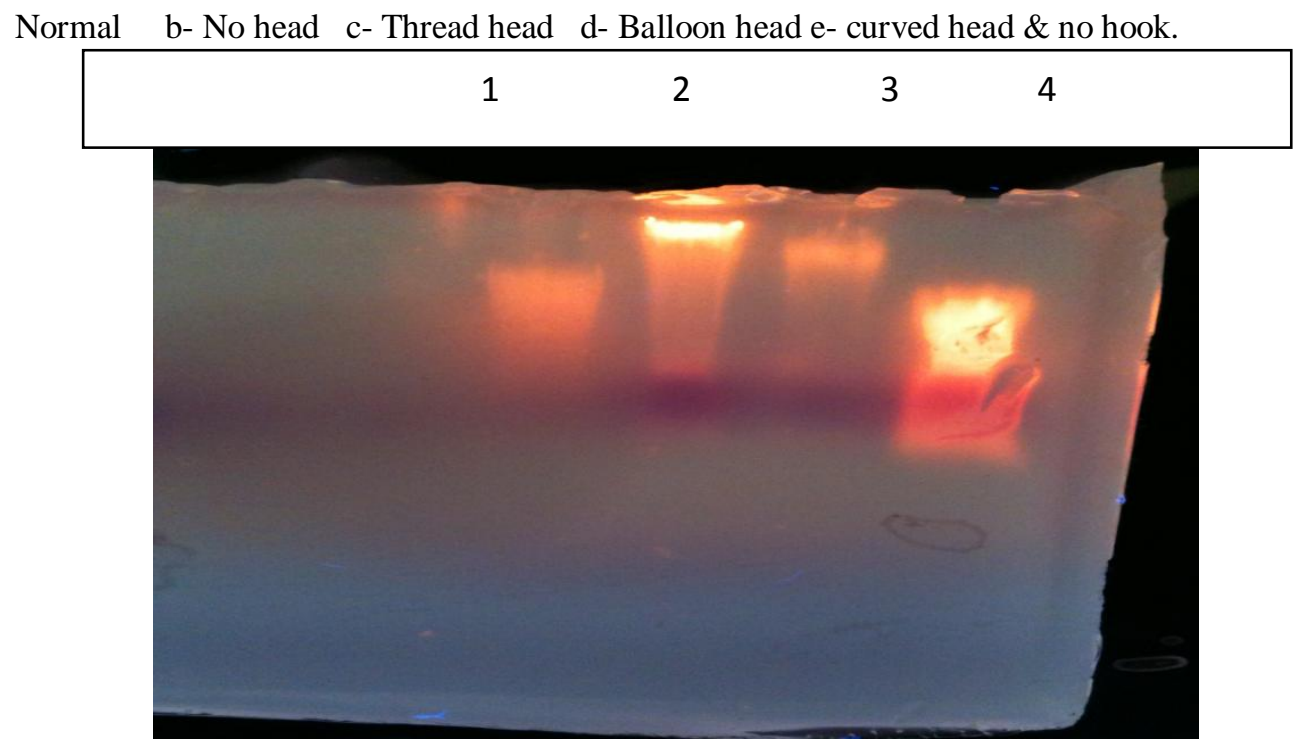

Fig. 2 . DNA electrophoresis.

Lane-1- UV+ Laser,Lane-2- Laser+ UV, Lane-3- Laser, Lane -4- UV.

DNA was electrophoresed by using $(1 \%)$ agrose gel electrophoresis at $(3 \mathrm{~V} / \mathrm{cm})$ for $(90 \mathrm{~min})$.

\section{Discussion:}

The He-Ne laser per-irradiation show a protection properties, which appeared on both sperm head abnormality and DNA damage against UVC light irradiation.

Table 1, and Fig.1 indicated that there are four sperm head abnormalities: no head ,thread head , balloon head and curved head \& no hook. The table also clarify that He-Ne laser irradiation lead to some degree of sperm head abnormality. This mean that, the used He-Ne laser dose in this work reveled a toxic effect but the percentage of the normal sperm head (24.8) is still higher than the UVC irradiation results (18.3). In contrast, He-Ne laser pre- irradiation against UVC irradiation show a significant rise in normal sperm head percentage (22.4). This indicating that the pre- irradiation of He-Ne laser decrease the sperm damaging effect of UVC irradiation. While no protection is observed when He-Ne laser performed post UVC irradiation (15.1). The results also demonstrate that sperms with no head, thread head and curved head \& no hook are higher after the UVC, and UVC+ Laser irradiation, but the balloon head is higher after the Laser, and Laser+ UVC irradiation. Since spermatogenesis is a complex cytomorphological event controlled by various sets of genes and their products. The final shape and size of spermatozoon in a species being determined at the very late phase of spermiogenesis(17). So, changes in sperm head morphology may be an applicable screen for radiation exposure doses effect on germ cells and events of late phase of spermiogenesis. This He-Ne laser toxic properties was reported by Banejee et. al on sperm head morphology of mice (16), and also by Taha et. al on lymphocyte cells survival and it's DNA damage (8).

So it can be concluded that, He-Ne laser irradiation by itself show a toxic effect leading to some degree of sperm head abnormality. While He-Ne laser pre ionizing irradiation (UVC) may be resulting in 
adversely influncing mammalian germ cell metabolism, which lowering the frequencies of sperm head abnormality.

From the DNA electrophoresis (Fig. 2), it can be seen that the UVC, and UVC+Laser irradition give a smear of DNA extraction, but only Laser and also Laser+UVC give one band . this results are similar to those reported by Ridha et.al., working on lymphocyte cells in vitro (18). Recently, researchers observed that He-Ne laser pre-irradiation leads to increase cell survival and reduce the DNA damage against ionizing radiations. The mechanism of the He-Ne laser induce protection appears to be a sort of adaptive response. He-Ne laser irradiation has been reported to lead to the generation of single Oxygen species and also increase the activity of the antioxidant enzymes(19,20).

Conclusion UVC shows a damaging effect on the DNA. This damage was reduced by the He-Ne laser pre- irradiation. Thus Laser pre-irradiation may be attributed to the induction of endogenous of radio protectors or which may be involved in DNA damage repair.

\section{References:}

[1] R.F. Lyon, R.P. Abergel, R.A. White., R.M .Dwyer, J.C. Castel \& J. Uitto Biostimulation of wound healing in vivo by a HeliumNeon Laser. Ann Plast Surg. 9 (1987):1-5.

[2] T.I.Karu. Photobiology of Low-power Laser effect. Healthy Phys. 56(1989): 691-704.

[3] T.I. Karu, L. Pxatibrat \& G. Kalendo. Irradiation with He-We Laser can influence the cytotoxic response of Hela cells to ionizing radiation. Int. Radiat. Biol.65(6)(1994):691-697.

[4] K. SH. Voskan Yan, N.V. Simonan, Ts. H. Avakyan\& A. G. Arutunyan. Effect of He-Ne Laser radiation on X-radiation sensitivity of Escherichia coli K-12 cells. Radiobiology. 25(1985):557-559.

[5] R. Kohli, P.K. Gupta \& A. Dube. He-Ne Laser pre-irradiation induced protection against UVC radiation in will E. coli strains K12AB1152. J. Radiat. Res., B: Biology; 153(2000):181-185, India.

[6] A. Pube, C. Bock, E. Bauer, R. Kohli, P.K.Gupta \& K.O. Gveulich. He-Ne Laser irradiation protects B-Lymphoblast from UVAinduced damage. Radiat. Environ. Biophys;40.(2000):77-82.

[7] R. Kohli \& P.K. Gupta. Irradiance dependence of He-Ne Laser- induced protection against UVC radiation in Escherichia coli strains . J. Photochemistry \& Photobiology, B: Biology. 69(2003):161-167.

[8] J.H.Taha, F.S Al-Ani., W.F Al-Siaidy. Protection properties of He-We Laser $(632.8 \mathrm{~nm})$ against UV- light $(253,7 \mathrm{~nm})$ on the Lymphocytes blood cells and its DNA . J. Fac. Med. Baghdad 54(3)(2012):247-251.

[9] P.E.Hockberger. A history of ultraviolet photobiology for humans, animals and microorganisms. J. Photochemistry \& Photobiology; 76(6) (2002):561-579.

[10] A. Wojcik, A.Bochenek, A. Lankoff, H. Lisowska, A. Pasjas, I. Szumiel, C.V. Sonntag \& G. Obe. DNA interstrand cross links are induced in cells pre labeled with 5- bromo-2 deoxyuridine and exposed to UVC radiation, J. photochem.\& Photobio.B:Biology 84(2006): $15-20$

[11] W.P. Hu, J.J. Wang, C.L.Yu ,C.C. Lan, G.Sh. Chen \& H.S.Yu. Helium-Neon Laser Irradiation Stimulates Cell Proliferation through photostimulatory effects in Mitochondria.J. Investigative Dermatology.127(2007):2048-2057.

[12] Y.P. Chen. Response of antioxidant defense system to Laser radiation apical meristem of Lsatis indigotica seedling exposed to UVB.Plant Signaling \& behavior.4(7)(2009):571-573.

[13] H. Komen \& G.H. Thorgaard,.Androgenesis,gynogenesis and the production of clones in fishes: A review, Aquaculture; 269(1-4) .(2007): 150-173.

[14] K. I. Ijiri \& , N .Egami. Hertwing effect caused by UV- irradiation of sperm of Oryzias latipes (teleost) and its photoreaction. Mutat. Res.69(1980):241-248.

[15] A. Dube, C.E. Bock,E.Bauer, R.Kohli, P.K. Gupta \& K.O. Greulih. He-Ne laser irradiation protects B-lymphoblasts from UVAinduced DNA damage. Radiant Environ. Biophys.40(2001):77-82.

[16] S. Banerjee, C.S.Chakrabarti \& L.K. Samanta. Effect of Laser exposure on scrotal sacs and sperm head morphology of Swiss albino mice, Mus musculus . Asian. J.Exp.Sci 19 (1)(2005):131-140.

[17] D. Ray, S.K.Ghosal \& C.R. Maiti. Pachytene frequency, RNA synthesis pattem in germ cell line of albino rats treated with ethinyl estradiol and dI- norgestrel. J.Exprtl.Biol.(10)(1991)15-19.

[18] F.D. Ridha, A.Z. Salih \& B.A. Abdul-Majeed. The effectof Laser radiation on DNA damage and repair. Fac. Med. Baghdad.54(2)(2012):163-166.

[19] R. Kohli, B. Bose\& P.K. Gupta. Induction of phr gene expression in E.coli strain KY 706/ppL-1 by He-Ne laser (632.8mm) irradiation. 60 (2001):136-142.

[20] L.P. Radinova, L.L. Concharova \& I.N. Ushova. Antioxident system of experimental animals exposed to hygienic doses of Laser irradiation. Chem. Abstracts. 106(1986):46-52. 